\title{
Community Based Study of Socio-demographic Determinants of Low Birth Weight Baby in Rural Area of Western Maharashtra
}

\author{
Avachat SS ${ }^{1}$, Phalke VD ${ }^{2}$, Kambale SV ${ }^{3}$ \\ ${ }^{1}$ Department of Community Medicine, Padmshree Dr Vitthalrao Vikhe Patil Foundations Medical College, \\ Ahmednagar, ${ }^{2}$ Department of Community Medicine, Rural Medical College, Loni, ${ }^{3}$ Department of Community \\ Medicine, KVM Medical College, Sullia, India
}

Received: April 10, 2014; Accepted: October 18, 2014

\begin{abstract}
Aims: There is only marginal reduction in proportion of low birth weight babies during last fifteen years. Birth weight is influenced by number of social, economic and demographic factors. The present study was conducted in a rural community to estimate the magnitude of low birth weight and to study the associated sociodemographic factors.
\end{abstract}

Methods: A cross sectional community based study was conducted in six randomly selected villages. Six hundred and fifty two under five children were randomly selected from these villages and data was collected by interviewing mothers of thesechildren with the help of predesigned questionnaire. Information pertaining to age, economic status of mother, antenatal care, birth spacing was collected and significance of these determinants was obtained by appropriate statistical tests.

Results: The proportion of low birth weight babies in present study, conducted in a rural community was $18.1 \%$. Significantly large proportion of low birth weight children were born to mothers belonging to lower socioeconomic status and lower educational status. $51 \%$ babies were born to mothers with age below 20 years and $25 \%$ babies were born with birth interval less than two years.

Conclusions: Maternal age, socioeconomic status, antenatal care and short birth spacing are the significant maternal determinants of the birth weight of the baby. Interventions relating to these determinants can reduce the problem of low birth weight in rural area

Keywords: low birth weight; sociodemographic factors; rural community.

\section{INTRODUCTION}

Low birth weight (LBW) is one of the most serious health challenges in developing as well as developed countries. The infant mortality rate is also higher in low birth weight babies. Birth weight is one of the important determinant of growth and survival of a child. According to international agreement low birth weight has been defined as birth weight of less than 2500 gms. ${ }^{1}$ Incidence of low birth weight in world is 25 million/ year (17\% of live births) and in India is $25-30 \% .^{2}$ There is only marginal reduction

\section{CORRESPONDENCE}

Dr Shubhada Sunil Avachat

Department of Community Medicine, Padmshree Dr Vitthalrao Vikhe Patil Foundations Medical College, Ahmednagar, India. Email: shubhadasunil@gmail.com

Phone: $+91-9423788664$ in proportion of low birth weight during last fifteen years. The proportion of low birth weight in India was $23 \%$ in rural area and $19 \%$ in urban area while the proportion of low birth weight in Maharashtra is $22 \%$ as reported in national family health survey-3 conducted in 2005-06. ${ }^{3}$

Birth weight is influenced by number of social, economic and demographic factors like maternal age, economic status, education, religion, etc. These factors in turn determine the quality of antenatal care, maternal nutrition, birth spacing and are important determinants of fetal nutrition and birth weight. Recognition of these factors is the essential and initial step to control the problem of low birth weight. The present study was conducted in a rural community to estimate the magnitude of low birth weight and its associated sociodemographic factors. 


\section{METHODS}

A cross sectional study was conducted in randomly selected six villages. These six villages were selected randomly by lottery method from two primary health centers located in the field practice area of Rural Medical College. Study participants were selected from anganwadis (functional unit of Integrated Child Development Scheme in India) of these villages. Every fifth child enrolled in anganwadi and having record of birth weight was selected for the study. Children not having record of birth weight were excluded from the study. Thus total six hundred and fifty two under five children were selected by systematic random sampling technique from these anganwadis. House to house survey was done and data was collected by interviewing the mothers of these under five children. Details of birth history, birth weight of the child were noted with the help of available records and by interviewing mothers of these children. Modified BG Prasad's classification was used to classify economic status. ${ }^{4}$ A predestined questionnaire was used to obtain the necessary information. The information was analyzed and tabulated. Percentages and proportions and chi square test were used for statistical analysis.

\section{RESULTS}

This study was conducted among six hundred and fifty two randomly selected underfive children from six villages. Out of these 652 children 118 (18.1\%). This study was conducted among six hundred and fifty two randomly selected underfive children from six villages. Out of these 652 children, 118 (18.1\%) had low birth weight. Among them 53.6\% were male and $46.4 \%$ were female. However this was not statistically significant (Table 1).

\begin{tabular}{|llll|}
\hline \multicolumn{4}{|l|}{ Table 1. Sex distribution of LBW babies $(\mathrm{n}=6 \mathbf{6 5 2})}$. \\
\hline Sex & $\begin{array}{l}\text { Birthweight }< \\
\mathbf{2 5 0 0} \mathbf{~ g m}\end{array}$ & $\begin{array}{l}\text { Birthweight }> \\
\text { 2500 gm }\end{array}$ & Total \\
Male & $63(53.38 \%)$ & $298(55.8 \%)$ & $\begin{array}{l}361 \\
(55.36 \%)\end{array}$ \\
Female & $55(46.62 \%)$ & $236(44.1 \%)$ & $\begin{array}{l}291 \\
(46.78 \%)\end{array}$ \\
Total & $118(18.1 \% \%)$ & $534(81.9 \%)$ & $\begin{array}{l}652 \\
(100 \%)\end{array}$ \\
\hline
\end{tabular}

$Z=0.47 p>0.05$ Not significant

Out of 118 LBW babies, majority 72 (61\%) was borne in Hindu families while $29.6 \%$ and $9.3 \%$ babies were born in Muslim and Christian families respectively. Majority of LBW were born to illiterate mothers and only $2.5 \%$ were borne to highly educated mothers. Majority of LBW babies were born in families with class IV and V economic status (Table 2).

\begin{tabular}{|lllll|}
\hline Table 2. Sociodemographic profiles of mothers of LBW babies $(\mathrm{n}=6 \mathbf{5 2})$. & & \\
\hline Chareteristics & Low birth weight & Normal birth weight & Total & \\
$<20$ years & $61(51.6 \%)$ & $151(28.2 \%)$ & 212 & \\
$>20$ years & $57(48.4 \%)$ & $383(71.7 \%)$ & 440 & $\begin{array}{l}\text { p }<0.01 \text { highly } \\
\text { Illiterate }\end{array}$ \\
Primary & $48(40.6 \%)$ & 109 & 157 & \\
Secondary\& higher & $33(27.9 \%)$ & 70 & 103 & $\mathrm{p}<0.01$ \\
secondary & $34(28.8 \%)$ & 324 & 358 & \\
Graduate\& above & $03(2.5 \%)$ & 31 & 34 & \\
& & & & \\
Economic class I & $02(1.6 \%)$ & 20 & 22 & \\
Economic class II & $08(6.7 \%)$ & 62 & 70 & \\
Economic class III & $18(15.25 \%)$ & 184 & 202 & $\mathrm{p}<0.01$ \\
Economic class IV & $32(27.11 \%)$ & 161 & 193 & \\
Economic class V & $58(49.5 \%)$ & 107 & 165 & \\
\hline
\end{tabular}


Birth spacing less than two years was noted in $27.1 \%$ of LBW babies as compared to $17.8 \%$ of normal birth weight babies. Significant association was observed between birth interval and birth weight (Table 3 ).

Highly significant association was observed between antenatal care taken by mother and birth weight of a child (Table 4).

\begin{tabular}{|llll|}
\hline \multicolumn{4}{|l|}{$\begin{array}{l}\text { Table 3. Association of birth spacing and birth } \\
\text { weight }(\mathrm{n}=652)\end{array}$} \\
\begin{tabular}{|l} 
Birth \\
spacing
\end{tabular} & $\begin{array}{l}\text { Low birth } \\
\text { weight }\end{array}$ & $\begin{array}{l}\text { Normal } \\
\text { birth } \\
\text { weight }\end{array}$ & Total \\
<two years & $32(27.1 \%)$ & $95(17.8 \%)$ & 127 \\
>two years & $86(62.9 \%)$ & $\begin{array}{l}439 \\
(82.2 \%)\end{array}$ & 525 \\
Total & $118(100 \%)$ & $534(100 \%)$ & 652 \\
\hline
\end{tabular}

Table 4. Association of utilization of antenatal care and birth weight $(\mathrm{n}=652)$.

\begin{tabular}{|llll|}
\hline $\begin{array}{l}\text { Antenatal } \\
\text { care taken }\end{array}$ & $\begin{array}{l}\text { Low birth } \\
\text { weight }\end{array}$ & $\begin{array}{l}\text { Normal } \\
\text { birth } \\
\text { weight }\end{array}$ & Total \\
Yes & $55(10.11 \%)$ & $\begin{array}{l}489 \\
(89.8 \%)\end{array}$ & $\begin{array}{l}(100 \%) \\
\text { No }\end{array}$ \\
Total & $63(58.33 \%)$ & 45 & 108 \\
$(41.67 \%)$ & $(100 \%)$ \\
\hline
\end{tabular}

\section{DISCUSSION}

Out of six fifty two under five children, 118 (18.1\%) children had low birth weight. As reported in NFHS3, the proportion of low birth weight babies was $23 \%$ in India and $22 \%$ in Maharashtra. Out of six fifty two study subjects i.e. underfive children, 118 (18.1\%) children had low birth weight. As reported in NFHS3, the proportion of low birth weight babies in $23 \%$ in rural area of India and in Maharashtra was $22 \%$. In the study conducted by Radhakrishnan et althe proportion of of low birth weight was $18 \%$ which is similar to our finding. ${ }^{5}$ Antonisamy et al ${ }^{6}$ in their study mentioned that the LBW proportion has declined from $27.2 \%$ to $15.9 \%$ in rural area. In a hospital-based study conducted by Joshi et al, ${ }^{7} 34.37$
$\%$ newborns were LBW. This high proportion could be due to the fact that the study was hospital based and selection bias might have occurred.

There was no significant difference in male and female babies and both the sexes were equally affected in our study (Table 1). Similar finding was observed by Ashtekar et al. ${ }^{8}$ Education and economic status of mother had significant impact on the birth weight of the child. This could be explained by proper maternal nutrition, awareness and utilization of health services by mother. In our study also significant association was observed between education, economic status and birth weight (Table 2). Similarly Joshi et al ${ }^{9}$ observed that $52 \%$ LBW babies were borne to illiterate women and the incidence of low birth weight decreases with increase in socioeconomic status. Also in study conducted byAnandet $\mathrm{al}^{10}$ majority of low birth weight babies were borne to illiterate mothers and he also mentioned that the number of LBW decreases with increase in per capita income.

Babies born to mothers less than 20 years agewere low birth weight; similar finding was observed by Ashtekar et $\mathrm{al}^{8}$ in their study. However Anand et $\mathrm{al}^{10}$ observed that majority of low birth weight babies were born to mothers of age less than 20 years. Birth spacing influences fetal nutrition and hence birth weight of the child. In our study low birth weight was significantly associated with birth spacing less than two years. Similar finding was observed by Kumar ${ }^{11}$ in his community based study of 'birth spacing and its bearing on birth weight' there was direct relation of birth weight and birth interval. In his study 49 mothers out of 104 had less than 29 months birth spacing. In study conducted by Deswal et al ${ }^{12} 40 \%$ LBW babies were born with birth interval less than two years.

Maternal nutrition and anemia are the important determinants of birth weight of a child and are more prevalent in Indian Women. Proper antenatal care is an important remedy to reduce low birth weight to reduce low birth weight. In our study also low birth weight babies were significantly more common in mothers who did not receive any antenatal care $(\mathrm{p}$ $<0.001$ ). Similar findings were observed in study conducted by Agarwal et al, ${ }^{13}$ significant association was found between non utilization of antenatal care and low birth weight. In studies conducted by Joshi et 
$\mathrm{al}^{9}$ and Deswal et $\mathrm{al}^{12} 61.7 \%$ and $21.3 \%$ babies were born to mothers who did not received antenatal care.

\section{CONCLUSIONS}

The percentage of low birth weight in our study was 18.1\%. Sociodemographic factors like maternal age less than 20 years, low education and poor economic status were significantly associated with low birth weightduration of birth spacing and proper antenatal care significantly influenced the birth weight of the child. Simple strategies like proper diet, antenatal care and awareness regarding family planning servicescan definitely help to reduce the problem of low birth weight.

\section{DISCLOSURE}

The authors report no conflicts of interest in this work.

No violation of human rights and safety.

Funding: Nil

\section{REFERENCES}

1. Park K, editor. Textbook of preventive and social medicine. 22nd edn. India: Bhanot publishers; 2013. p. 494-6.

2. WHO. International statistical classification of diseases and related health problems, tenth revision. Geneva: WHO; 2004

3. National Family Health Survey of India- 2005. [Cited 2012 May 2]. Available from: http://www.rchiips.org/nfhs/report. shtm

4. Mahajan B. Gupta M. Text book of preventive and social medicine. 3rd ed. India: Jaypee publishers; 2005. p.117-8

5. Radhakrishnan T, Thankappan K. Socioeconomic and demographic factors associated with birth weight results of a community based study in Kerala, Achuta Menon Center for health science study 1997. [Cited 2001 December 12]. Available from: http// www.lbwproject lbw-scimst. htm.

6. Antonisamy B, Rao P, Sivram M. Changing scenario of birthweight in South India. Indian Pediatrics. 1994;(31):9318
7. Joshi H. Risk factors associated with low birth weight in newborns IJCM. 2005;30(4):142-3.

8. Ashtekar S, Kulkarni M.Analysis of birth weights of rural hospital newborns. IJCM. 2010;35(2):252-5.

9. Joshi S, Pai N. The maternal biosocial determinants on the birthweight in a slum area of greater Mumbai. IJCM. 2000;25(3):121-3.

10. Kiran A. A study of factors affecting low birth weight. IJCM. 2000;25(2):129-31.

11. Kumar V. Community based study of birth spacing and its bearing on birth weight. IJCM. 1992;17(1):15-9.

12. Deswal B. Study of risk factors for low birth weight babies. IJCM. 1999;24(3):27-9. 